\title{
Effective Treatment of Verapamil Intoxication with 4-Aminopyridine in the Cat
}

\author{
S. Agoston, E. Maestrone, E. J. van Hezik, J. M. Ket, \\ M. C. Houwertjes, and D. R. A. Uges \\ Research Group of the Institutes of Anesthesiology, Clinical \\ Pharmacology, and Hospital Pharmacy, State University of \\ Groningen, 9713 EZ Groningen, The Netherlands
} bstract. To study the value of 4 -aminopyri-
dine as an antidote to verapamil intoxication, we subjected 12 adult cats to verapamil poisoning by administering doses of $4.0-25.0 \mathrm{mg} / \mathrm{kg}$ verapamil by intravenous infusion. Six animals were given 4-aminopyridine $2 \times 0.5$ $\mathrm{mg} / \mathrm{kg}$ i.v. after the verapamil infusion was stopped and the other six animals (the control group) were not. Verapamil caused profound cardiovascular depression and also partial neuromuscular block, both of which were completely reversed by 4-aminopyridine within $50 \mathrm{~min}$, in spite of extremely high serum verapamil concentrations (ranging between 3,700 and 13,500 ng/ml). The six animals that received 4-aminopyridine survived the verapamil intoxication, whereas four of the six animals in the control group died. The results suggest that 4-aminopyridine may be useful in the treatment of verapamil intoxication.

\section{Introduction}

Verapamil is a well-known and widely used antianginal, antidysrhythmic, and antihypertensive agent. However, its largescale clinical use has been paralleled by an increase in the incidence of deliberate and accidental poisonings with the drug. The main pharmacological actions of verapamil-inhibitory effects on myocardial contractility and cardiac pacemaker activity, and profound vascular smooth muscle relaxation-can be overcome by calcium and catecholamines. Indeed, in most of the reported cases of serious verapamil poisoning, the cardiovascular complications were successfully treated with intra-

Dr. Maestrone is a visiting scientist from the Ospedale Civile, Sondrio, Italy.

Received for publication 14 October 1982 and in revised form 12 January 1984.

J. Clin. Invest.

(c) The American Society for Clinical Investigation, Inc.

$0021-9738 / 84 / 05 / 1291 / 06 \$ 1.00$

Volume 73, May 1984, 1291-1296

venous injections of calcium gluconate, norepinephrine, artificial cardiac pacing, or by a combination of these (1-6).

Massive verapamil overdose does not, however, always respond to conventional treatment (7). This prompted us to investigate the possible beneficial effects of 4-aminopyridine in verapamil intoxication in an animal model. This compound increases transmembrane calcium influx, which facilitates synaptic transmission because of increased calcium-dependent transmitter release in a variety of tissues (8-10). At higher dosages it may also increase muscle contractility, thereby increasing the availability of calcium to the contractile mechanism not only from extracellular sources but also from intracellular stores (11, 12). 4-Aminopyridine has been used clinically for almost $10 \mathrm{yr}$ as an antagonist of nondepolarizing neuromuscular blocking agents in Bulgaria, where it is marketed under the trade name Pymadine (Pharmachim, Sofia) (13).

The experiments reported here investigated whether 4-aminopyridine alone can counteract the hemodynamic and possible neuromuscular $(14,15)$ effects that result from a massive overdose of verapamil (which otherwise would be lethal) in artificially ventilated cats.

\section{Methods}

Two separate groups of six cats each (Table I) were studied. In all experiments the cats were anesthetized with $40 \mathrm{mg} / \mathrm{kg}$ pentobarbitone sodium intraperitoneally. After intubation, ventilation was maintained throughout the experiment with a respirator pump (type 1905; B. Braun Instruments, San Francisco, CA) at a rate of 30/min and a tidal volume of air of $18 \mathrm{ml} / \mathrm{kg}$. Blood pressure was monitored by a pressure transducer (P23 Db; Statham Instruments, Inc., Oxnard, CA) connected to a polyethylene cannula inserted into the carotid artery. Through the same cannula arterial blood samples were taken for determination of verapamil concentrations during the experiments. Another polyethylene cannula was placed in the right femoral vein and was used to inject drugs. To control the general condition of the animals and follow drug effects, the electrocardiogram (ECG) ${ }^{1}$ (ECG-pulse monitor MS-35; Electrodyne Co., Milwaukie, OR) was monitored throughout the experiments. Rectal temperature was continuously measured and maintained at $37.5 \pm 0.5^{\circ} \mathrm{C}$

1. Abbreviations used in this paper: AV, atrioventricular; ECG, electrocardiogram. 
with a heating blanket placed under the cats. An infusion of glucose $2.5 \%$ in saline $0.45 \%$ was maintained at a rate of $8 \mathrm{ml} / \mathrm{kg}$ per h during the experiments.

Experimental protocol. Three animals in the first group (A) were subjected, on two occasions $1 \mathrm{wk}$ apart, to verapamil intoxication. Verapamil (dissolved in water for intravenous injection) was infused at the rate of $8 \mathrm{mg} / \mathrm{kg}$ per h for $60 \mathrm{~min}$ or until one of the following critical signs appeared: an $80 \%$ drop in the mean blood pressure, an $80 \%$ decrease in the heart rate, or complete atrioventricular (AV) block. If none of these critical signs had appeared by the end of the 1-h infusion period, small bolus doses $(0.25 \mathrm{mg} / \mathrm{kg})$ of verapamil were given until one occurred. At that moment, 4-aminopyridine $0.5 \mathrm{mg} / \mathrm{kg}$ i.v. was given twice, 5 min apart. All three cats in this group survived the experiment and were extubated within $180 \mathrm{~min}$ of the administration of 4-aminopyridine. 1 wk later, the same animals were again subjected to the same treatment with verapamil; this time, however, 4-aminopyridine was not given when the verapamil-induced critical hemodynamic changes appeared.

The remaining three animals in the first group (A) received the same treatment under the same experimental conditions as the other animals in this group had received on the first occasion (i.e., when 4-aminopyridine was given when the critical hemodynamic changes occurred). However, to demonstrate the possible effects of toxic doses of verapamil on neuromuscular transmission, the twitch response of the left tibialis anterior muscle-elicited by supramaximal square wave stimuli of 0.2 -ms duration applied to the common peroneal nerve at $0.1 \mathrm{~Hz}$-was also recorded, by means of a Hottinger-Baldwin force displacement transducer (Mess Technik, Darmstadt, West Germany) and a two-channel polygraph recorder (MFE Corp., Salem, NH). These animals survived the verapamil intoxication but had to be sacrificed at the end of the experiment because the neuromuscular preparation had inflicted surgical damage.

The second group of six animals (the control group, B) received the same treatment with verapamil under similar experimental conditions as those in group A but were not given 4-aminopyridine after treatment with verapamil. In this group the twitch response of the tibialis anterior muscle was not monitored. Artificial ventilation was continued in all animals in this control group for $180 \mathrm{~min}$ after verapamil infusion was stopped or until the animal died, whichever occurred first.

In all experiments blood samples were obtained before the verapamil infusion was begun and at 10 -min or, later, at 15 -min intervals for determination of verapamil and norverapamil concentrations. The samples were analyzed by one of the authors (D. R. A. Uges) in the hospital pharmacy by high pressure liquid chromatography.

Heart rate and mean arterial blood pressure changes were statistically analyzed by the Wilcoxon test for paired and, when appropriate, unpaired data, and the difference in mortality between the group treated with 4 aminopyridine and the control group was assessed by Fisher's exact test. Differences were considered to be significant if $P$ was $<0.05$.

\section{Results}

The individual data from the experiments are summarized in Table I.

Survival. All animals in group A survived the verapamil intoxication after the administration of 4-aminopyridine. In the control group (B), where 4-aminopyridine was not used, three

Table I. Individual Changes in Heart Rate and Mean Arterial Blood Pressure due to Verapamil (V) and 4-Aminopyridine (4-AP) in the Cat

\begin{tabular}{|c|c|c|c|c|c|c|c|c|c|c|c|c|c|}
\hline \multirow[b]{3}{*}{ Group } & \multirow{3}{*}{$\begin{array}{l}\text { Experi- } \\
\text { ment } \\
\text { no. }\end{array}$} & \multicolumn{5}{|c|}{ Heart rate } & \multicolumn{5}{|c|}{ Mean arterial blood pressure } & \multirow{3}{*}{$\begin{array}{l}\text { AV block during } \\
\mathrm{V} \text { infusion }\end{array}$} & \multirow[b]{3}{*}{$\begin{array}{l}\text { Death after } \\
\mathrm{V} \text { infusion }\end{array}$} \\
\hline & & \multirow{2}{*}{$\begin{array}{l}\text { Before } \\
\text { V }\end{array}$} & \multirow{2}{*}{$\begin{array}{l}\text { After } \\
\text { V }\end{array}$} & \multicolumn{3}{|c|}{ After 4-AP } & \multirow{2}{*}{$\begin{array}{l}\text { Before } \\
\mathrm{v}\end{array}$} & \multirow[b]{2}{*}{$\begin{array}{l}\text { After } \\
\text { V }\end{array}$} & \multicolumn{3}{|c|}{ After 4-AP } & & \\
\hline & & & & $10 \mathrm{~min}$ & $30 \mathrm{~min}$ & $50 \mathrm{~min}$ & & & $10 \mathrm{~min}$ & $30 \mathrm{~min}$ & $50 \mathrm{~min}$ & & \\
\hline & & & & & & & & & & & & $\min$ & $\min$ \\
\hline \multirow[t]{9}{*}{ A } & 1 & 175 & 68 & 175 & 200 & 200 & 130 & 40 & 130 & 150 & 150 & 60 & $\mathbf{S}$ \\
\hline & la & 175 & 60 & - & - & - & 100 & 20 & - & - & - & 56 & 21 \\
\hline & 2 & 170 & 40 & 50 & 90 & 140 & 100 & 45 & 100 & 115 & 110 & 70 & $\mathbf{S}$ \\
\hline & $2 a$ & 170 & 35 & - & - & - & 75 & 30 & - & - & - & 33 & 40 \\
\hline & 3 & 170 & 36 & 85 & 165 & 165 & 90 & 50 & 100 & 100 & 100 & 62 & $\mathbf{S}$ \\
\hline & $3 a$ & 125 & 80 & - & - & - & 100 & 50 & - & - & - & 50 & $\mathbf{S}$ \\
\hline & $4^{*}$ & 180 & 30 & 70 & 110 & 150 & 100 & 30 & 70 & 120 & 130 & 55 & S \\
\hline & $5^{*}$ & 170 & 50 & 65 & 60 & 120 & 100 & 50 & 70 & 60 & 80 & 50 & $S$ \\
\hline & $6^{*}$ & 145 & 75 & 150 & 150 & 150 & 110 & 60 & 110 & 100 & 100 & 56 & $\mathbf{S}$ \\
\hline \multirow[t]{6}{*}{ B } & 1 & 142 & 60 & - & - & - & 88 & 42 & - & - & - & 40 & 58 \\
\hline & 2 & 133 & 80 & - & - & - & 106 & 62 & - & - & - & 30 & $19 \mathrm{~h}$ \\
\hline & 3 & 173 & 90 & - & - & - & 120 & 50 & - & - & - & 60 & $\mathbf{S}$ \\
\hline & 4 & 165 & 75 & - & - & - & 98 & 35 & - & - & - & 20 & 33 \\
\hline & 5 & 138 & 80 & - & - & - & 85 & 42 & - & - & - & 10 & 45 \\
\hline & 6 & 136 & 85 & - & - & - & 120 & 30 & - & - & - & 19 & $\mathbf{S}$ \\
\hline
\end{tabular}

a, second exposure, no 4-AP given; $S$, survived. * Twitch response monitored. 
animals died within $60 \mathrm{~min}$ of termination of the verapamil infusion and one animal (group B, No. 2; Table I) died after $19 \mathrm{~h}$; two animals (group B, Nos. 3 and 6; Table I) survived the experiment. The difference in survival between the two groups was found to be statistically significant $(P<0.05$ by Fisher's exact test).

Of the three animals in group A (Table I) that were not given 4-aminopyridine after the second exposure to verapamil, two died within $40 \mathrm{~min}$ of the end of the infusion of verapamil and one animal (group A, No. 3a, Table I) survived. Since these animals were very sick and weak for $3 \mathrm{~d}$ after the first exposure, it is possible that the results obtained after the second exposure to verapamil ( $7 \mathrm{~d}$ after the first) were influenced by the first treatment; these experiments were, therefore, excluded from further evaluation of the results.

Neuromuscular effects. In the three animals studied (group A, Nos. 4, 5, and 6; Table I) only $20.0 \pm 7.0 \%$ depression of the twitch height was observed after the excessive doses of verapamil were used. Statistically these changes in the twitch height were not significantly different from the control values. The neuromuscular effects of verapamil observed in this study were restored to control values within $50 \mathrm{~min}$ of the administration of 4-aminopyridine.

Hemodynamic changes. In all experiments verapamil induced a dramatic fall in the mean arterial blood pressure and heart rate, as well as complete AV block at various times during infusion (Table I). These changes were restored toward control values within $50 \mathrm{~min}$ of the administration of 4-aminopyridine. The cardiovascular effects of verapamil and 4-aminopyridine during a typical experiment (group A, No. 1; Table I) are shown in Fig. 1. It should be emphasized that the 4-aminopyridineinduced improvement in the heart rate and blood pressure oc- curred while the serum verapamil concentrations were still extremely high (as in Fig. 1).

The changes in heart rate and mean arterial blood pressure in group A and group B are summarized in Fig. 2. To demonstrate the difference between the spontaneous and 4-aminopyridine-induced recovery from the hemodynamic changes after verapamil, the 3-h values from experiments Nos. 2, 3, and 6 in Group B (Table I) are also included in Fig. 2. In both groups A and B, verapamil caused a significant fall in heart rate and mean arterial blood pressure $(P<0.025)$ as compared with control values. There was a significant improvement $(P<0.025)$ in both parameters $10 \mathrm{~min}$ after the administration of 4-aminopyridine (when compared with post-verapamil values). Further improvement was observed 30 and $50 \mathrm{~min}$ after the injection. Within $50 \mathrm{~min}$ the hemodynamic status was fully restored. The improvement in the heart rate at 50 min was significantly greater than at $10 \mathrm{~min}$ after 4 -aminopyridine $(P<0.025)$, whereas the difference in the mean arterial blood pressure at 10 and $50 \mathrm{~min}$ was not significant.

The three animals (Nos. 2, 3, and 6) in group B that survived the verapamil intoxication for at least $3 \mathrm{~h}$ recovered their cardiovascular parameters very slowly. In this group the heart rate and blood pressure values $3 \mathrm{~h}$ after the end of the verapamil infusion were still lower than the 10 -min values observed after 4-aminopyridine was given to group A. The 4-aminopyridineinduced improvement in heart rate and blood pressure $50 \mathrm{~min}$ after the administration of this drug in Group A was statistically significantly greater $(P<0.05)$ than the spontaneous recovery $3 \mathrm{~h}$ after verapamil infusion was stopped in these group B animals. The ECG changes were similar in all experiments, showing complete AV block preceded by sinus arrest, nodal rhythm, or idioventricular escape rhythm. In most of the experiments the

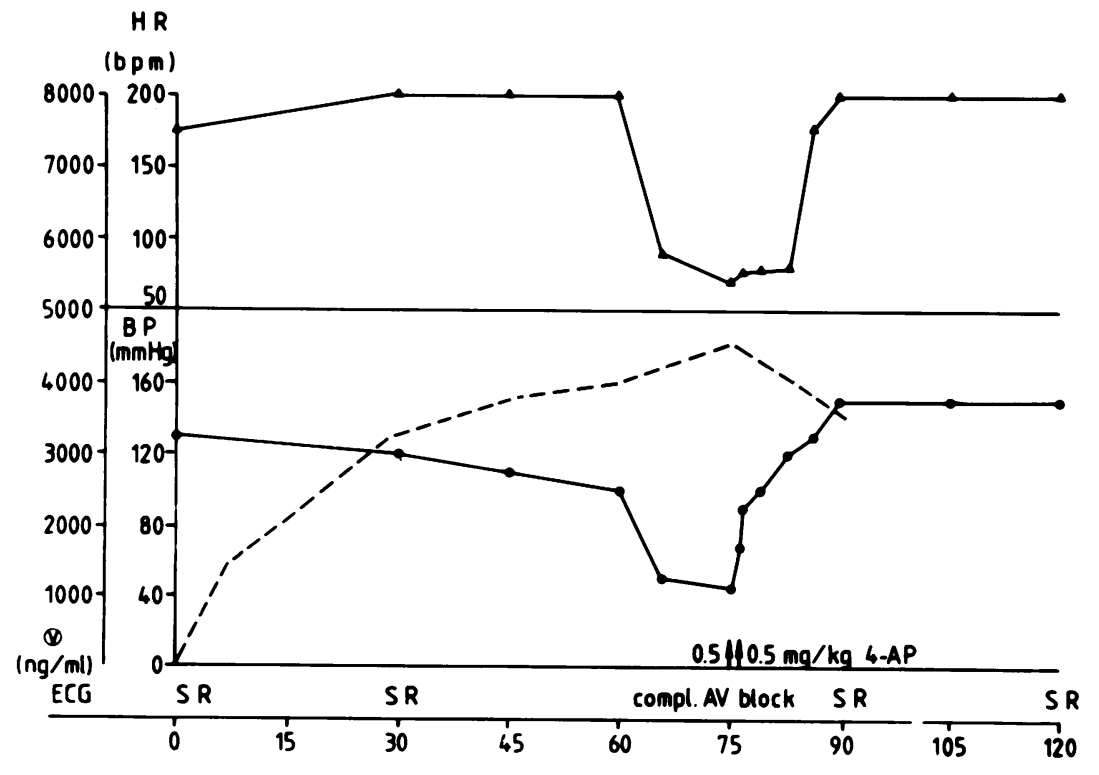

Figure 1. Time course of events during experiment 1 in group A (see also Table I). Outer scale along ordinate: serum concentrations of verapamil (nanograms per milliliter; dashed line). Inner scale along ordinate: $\Delta$, heart rate (HR; beats per minute). Inner scale along ordinate: $\bullet$, mean arterial blood pressure (BP; $\mathrm{mmHg}$ ). Abscissa: time (minutes). Arrows indicate time at which 4-aminopyridine (4-AP) was given (SR, sinus rhythm). 


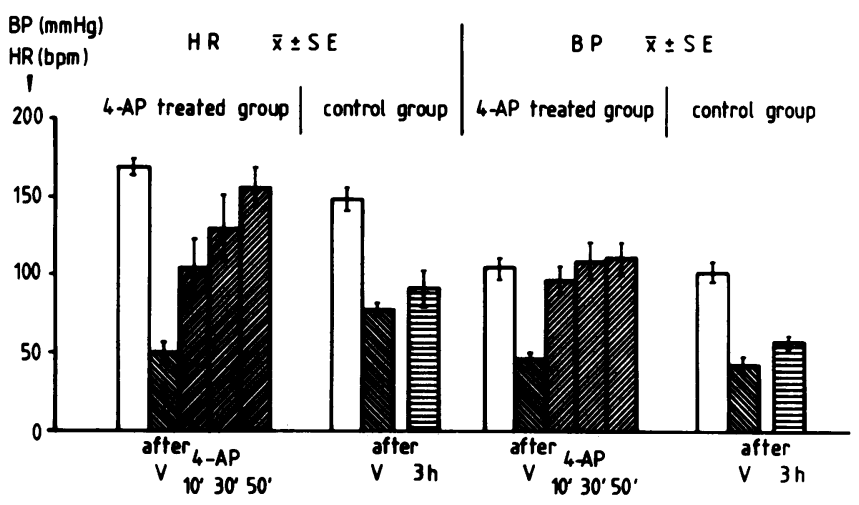

Figure 2. Changes in heart rate and mean arterial blood pressure $(B P ;$ mean \pm SE) after verapamil (V) was given $(\mathbb{Q})$, and 10,30 , and 50

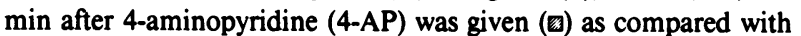
control values (ㅁ). Spontaneous recovery in the heart rate (HR) and mean arterial blood pressure $3 \mathrm{~h}$ after the cessation of the verapamil infusion (国). (Experiments No. 2, 3, and 6 in group B, see also Table I.)

ECG abnormalities were restored to normal $30 \mathrm{~min}$ after the injection of 4-aminopyridine, and in all cases sinus rhythm was reestablished within $50 \mathrm{~min}$ of the administration of this drug. The total dose of verapamil varied between 4.0 and $25.0 \mathrm{mg} /$ $\mathrm{kg}$, and the maximum serum verapamil concentration varied between 3,700 and $13,500 \mathrm{ng} / \mathrm{ml}$ in the various experiments. In the serum specimens analyzed, norverapamil could only occasionally be demonstrated.

\section{Discussion}

In this study 4-aminopyridine seemed able to protect artificially ventilated cats from death after massive verapamil intoxication. Another simultaneously conducted study (16) in our laboratory revealed that 4-aminopyridine was more effective than saline or calcium levulate in reversing less profound cardiovascular depression after $1.3 \mathrm{mg} / \mathrm{kg}$ verapamil was given intravenously in the rabbit. However, in the same study, earlier administration of 4-aminopyridine failed to reduce toxicity and prevent mortality after $7.0 \mathrm{mg} / \mathrm{kg}$ verapamil was given intravenously. In that study (16) the animals breathed spontaneously throughout the experiments, a fact which (in addition to species differences) might explain the differences between the results of these two studies.

Artificial ventilation might be a very important factor in the treatment of massive verapamil intoxication and should be viewed not only as a supportive measure to reduce tissue hypoxia from the subsequent cardiogenic shock but also as a way to protect against the hypoxia and hypercarbia that result from impaired spontaneous ventilation because of the possible neuromuscular effects of verapamil. We observed only weak neuromuscular blocking effects from toxic doses of verapamil.

Other investigators (14) have reported significant potentiation of the neuromuscular blocking effects of vecuronium bromide (a new nondepolarizing relaxant) by verapamil in the cat, suggesting that calcium antagonists, including verapamil, might decrease the margin of safety of neuromuscular transmission. Using a different experimental design, Kraynack et al. (15) demonstrated significant depression of the indirectly evoked muscle twitch height 90-180 min after the injection of verapamil in barbiturate-anesthetized cats. The slow development of a verapamil-induced block may explain why we observed only weak neuromuscular paralysis in our experiments. Although the mechanism for this effect is unclear, verapamil's action on neuromuscular transmission might adversely influence survival after massive intoxication with this compound in nonventilated subjects.

The hemodynamic effects of verapamil are due to a block of slow calcium channels and include a decrease of myocardial contractile force, suppression of impulse production in cardiac pacemaker tissues, and inhibition of excitation-contraction coupling in vascular smooth muscle, which results in profound vasodilatation in the coronary and systemic circulations (17). At therapeutic dosages, calcium antagonists also suppress calcium-dependent excitation-secretion coupling $(18,19)$; after toxic doses of these agents, certainly, this can produce profound endocrine disturbances in addition to the existing hemodynamic chaos (7).

4-Aminopyridine indirectly increases transmembrane calcium movement by blocking voltage-dependent potassium channels in excitable membranes (20-22). There is, however, experimental evidence that suggests that in addition to potassium channel blockade, this drug might also promote inward calcium currents by direct action on the voltage-dependent calcium channels $(23,24)$. Blockade of potassium efflux may prolong nerve terminal action potentials, which in turn cause an increased inward calcium current and increased evoked transmitter release $(25,26)$. The above mechanisms may explain the facilitatory actions of 4-aminopyridine on transmitter release, not only in cholinergic structures but also in sympathetic neuroeffector junctions in the spleen of the cat (27), the rabbit vas deferens (28), and the isolated sino-atrial node of the dog heart (29). This drug produces positive inotropic effects, not only by catecholamine release but also by direct action on the heart muscle (30). It is more likely, however, that increased peripheral resistance is the explanation in the present study for the complete restoration of the mean arterial blood pressure before the full normalization of the heart rate (Fig. 2). In reference to the results it is worthwhile to mention that 4-aminopyridine increases respiratory drive, as demonstrated by quantitative measurement of the action potential frequency in the phrenic nerves of vagotomized cats (31), and it also reverses neuromuscular block that is due to nondepolarizing muscle relaxants (13) or to verapamil, as has been observed in our study. Besides its facilitatory effects at the neuromuscular junction, 4-aminopyridine also has a direct effect on skeletal muscle, increasing its contractility (12).

The wide spectrum of pharmacological actions of 4-ami- 
nopyridine on calcium-dependent biological functions in general and on the cardiovascular system in particular, together with its ability to promote the release of certain hormones from rat pituitary cells (32) and insulin from isolated islets of Langerhans (33), suggests that this compound deserves a trial in the treatment of massive verapamil intoxication in man in cases where conventional measures have failed.

Therapeutic concentrations after $10 \mathrm{mg}$ verapamil is given intravenously range from 20 to $40 \mathrm{ng} / \mathrm{ml}$ plasma (34). In patients with symptoms of serious verapamil poisoning, serum concentrations varying between 590 and $3,200 \mathrm{ng} / \mathrm{ml} \mathrm{(2-4)} \mathrm{have} \mathrm{been}$ reported. The serum verapamil concentrations observed in our study are thus much greater than those reported so far in human verapamil poisoning.

The clinical dosage of intravenous 4-aminopyridine used routinely in anesthesiology to reverse neuromuscular blockade is between 0.3 and $0.5 \mathrm{mg} / \mathrm{kg}$ (11). To avoid central nervous system stimulatory effects, which may occur after higher dosages, we administered $0.5 \mathrm{mg} / \mathrm{kg}$ 4-aminopyridine two times, $5 \mathrm{~min}$ apart, in our study. This dosage regimen seemed to effectively reverse the toxic effects of verapamil, which otherwise were lethal in most of the animals. More essential information about this compound and its human pharmacokinetics (35), and about ways to analyze and produce pharmaceutically parenteral (36) and oral (37) preparations has recently become available. We hope that the above information on 4-aminopyridine will encourage further studies with this compound in the treatment of verapamil intoxication in man.

\section{Acknowledgments}

We thank Professor W. C. Bowman (Department of Physiology and Pharmacology, University of Strathclyde, Glasgow) for discussing the manuscript, and we gratefully acknowledge the encouragement and criticism of Prof. D. Langrehr and Dr. F. J. Richardson (Institute of Anesthesiology, University of Groningen).

\section{References}

1. De Faire, U., and T. Lundman. 1977. Attempted suicide with verapamil. Eur. J. Cardiol. 63:195-198.

2. Gelbke, H. P., H. J. Schlicht, and G. G. Schmidt. 1977. Fatal poisoning with verapamil. Arch. Toxicol. 37:89-94.

3. Perkins, C. M. 1978. Serious verapamil poisoning: treatment with intravenous calcium gluconate. Br. Med. J. 2:1127.

4. Woie, L., and L. Storstein. 1981. Successful treatment of suicidal verapamil poisoning with calcium gluconate. Eur. Heart J. 2:239-242.

5. Immonen, P., A. Linkola, and E. Waris. 1981. Three cases of verapamil poisoning. Int. J. Cardiol. 1:101-105.

6. Hattori, V. T., W. J. Mandel, and T. Peter. 1982. Calcium for myocardial depression from verapamil. N. Engl. J. Med. 306:238.

7. Van der Meer, J., and E. van der Wall. 1983. Fatal acute intoxication with verapamil. Neth. J. Med. 26:130-132.

8. Vizi, E. S., J. van Dijk, and F. F. Foldes. 1977. The effect of 4aminopyridine on acetylcholine release. J. Neural. Transm. 41:265-274.

9. Al-Haboubi, H. A., W. C. Bowman, J. Huston, and A. O. Savage.
1978. Effects of 4-aminopyridine on the isolated parasympathetically innervated oesophagus of the domestic fowl chick. J. Pharm. Pharmacol. 30:517-518.

10. Leander, S., A. Arner, and B. Johansson. 1977. Effects of 4-aminopyridine on mechanical activity and noradrenaline release in the rat portal vein in vitro. Eur. J. Pharmacol. 46:351-361.

11. Bowman, W. C., and A. O. Savage. 1981. Pharmacological actions of aminopyridines and related compounds. Rev. Pure Appl. Pharmacol. Sci. 2:317-371.

12. Agoston, S., W. C. Bowman, M. C. Houwertjes, I. W. Rodger, and A. O. Savage. 1982. Direct action of 4-aminopyridine on the contractility of a fast contracting muscle in the cat. Clin. Exp. Pharmacol. Physiol. 9:21-34.

13. Stojanov, E., P. Vulchev, M. Shtrubova, and M. Marinova. 1976. Clinical electromyomechanographic and electromyographic studies in decurarization with Pymadine. Anaesth. Resus. Intens. Ther. 4:139142.

14. Anderson, K. A., and R. J. Marshall. 1983. The effects of calcium antagonists on the neuromuscular blocking actions of vecuronium bromide in anaesthetized cats. Br. J. Pharmacol. (Suppl.) 80:613P. (Abstr.)

15. Kraynack, B. J., N. W. Lawson, and J. Gintantos. 1983. Neuromuscular blocking action of verapamil in cats. Can. Anaesth. Soc. J. 303:242-247.

16. Wesseling, H., M. C. Houwertjes, C. D. J. de Langen, and H. J. Kingma. 1983. Hemodynamic effects of high dosages of verapamil and the lack of protection by 4-aminopyridine in the rabbit. Arch. Int. Pharmacodyn. Ther. 266:106-112.

17. Fleckenstein, A. 1977. Specific pharmacology of calcium in myocardium, cardiac pacemakers, and vascular smooth muscle. Ann. Rev. Pharmacol. Toxicol. 17:149-166.

18. Russel, J. T., and N. A. Thorn. 1974. Calcium and stimulussecretion coupling in the neurohypophysis. II. Effects of lanthanum, a verapamil analogue (D 600) and phenylamine on 45-calcium transport and vasopressin release in isolated rat neurohypophyses. Acta Endocrinol. (Copenhagen). 76:471-487.

19. Devis, G., G. Somers, E. van Obberghen, and W. J. Malaisse. 1975. Calcium antagonists and islet function. I. Inhibition of insulin release by verapamil. Diabetes. 24:547-551.

20. Pelhate, M., and Y. Pichon. 1974. Selective inhibition of potassium current in the giant axon of the cockroach. J. Physiol. (Lond.). 242:90-91P.

21. Yeh, J. Z., G. S. Oxford, C. H. Wu, and T. Narahashi. 1976. Interactions of aminopyridines with potassium channels of squid axon membranes. Biophys. J. 16:77-81.

22. Molgo, J. 1978. Voltage clamp analysis of the sodium potassium current in skeletal muscle fibres treated with 4-aminopyridine. Experientia (Basel). 34:1275-1276.

23. Lundh, H., and S. Thesleff. 1977. The mode of action of 4aminopyridine and guanidine on transmitter release from motor nerve terminals. Eur. J. Pharmacol. 42:411-412.

24. Illes, P., and S. Thesleff. 1978. 4-Aminopyridine and evoked transmitter release from motor nerve endings. Br. J. Pharmacol. 64:623629.

25. Katz, B., and R. Miledi. 1967. Modifications of transmitter release by electric interference with motor nerve endings. Proc. $R$. Soc. Lond. B. Biol. Sci. 167:1-7.

26. Katz, B., and R. Miledi. 1967. The release of acetylcholine from nerve endings by graded electric currents. Proc. R. Soc. Lond. B. Biol. Sci. 167:23-38. 
27. Kirpekar, M., S. M. Kirpekar, and J. C. Prat. 1977. Effect of 4aminopyridine or release of noradrenaline from perfused cat spleen by nerve stimulation. J. Physiol. (Lond.) 272:517-528.

28. Johns, A., D. S. Golko, P. A. Lanzon, and D. M. Paton. 1976. The potentiating effects of 4-aminopyridine on adrenergic transmission in the rabbit vas deferens. Eur. J. Pharmacol. 38:71-78.

29. Yanagisawa, T., K. Satok, and N. Toira. 1978. Excitation of autonomic nerves by 4-aminopyridine in the isolated, blood perfused sino-atrial node preparation of the dog. Eur. J. Pharmacol. 49:189-192.

30. Yanagisawa, T., and N. Toira. 1979. Positive inotropic effect of 4-aminopyridine on dog ventricular muscle. Naunyn Schmiedebergs Arch. Pharmakol. Exp. Pathol. 307:207-212.

31. Folgering, H., J. Rutten, and S. Agoston. 1979. Stimulation of phrenic nerve activity by an acetylcholine releasing drug: 4-aminopyridine. Pfluegers Arch. Eur. J. Physiol. 379:181-189.

32. Sand, O., E. Hang, and K. M. Gantvik. 1980. Effects of thyroliberin and 4-aminopyridine on action potentials and prolactin release and synthesis in rat pituitary cells in culture. Acta Physiol. Scand. 108:247-252.

33. Bowman, W. C. 1982. Further miscellaneous actions of aminopyridines and related compounds. Adv. Biosci. 35:335-341.

34. Eickelbaum, M., P. Birkel, E. Grube, U. Bütemann, and A. Somogyi. 1980. Effects of verapamil on P-R-intervals in relation to verapamil plasma levels following single i.v. and oral administration and during chronic treatment. Klin. Wochenschr. 58:919-925.

35. Uges, D. R. A., Y. J. Sohn, B. Greijdanus, and A. H. J. Scaf. 1982. 4-Aminopyridine kinetics. Clin. Pharmacol. Ther. 31:587-593.

36. Uges, D. R. A., and T. Huizinga. 1981. 4-Aminopyridine: analysis of the substance and a method for the preparation of solution for injection in man. Pharm. Acta Helv. 56:158-162.

37. Uges, D. R. A., A. Versluis, J. M. Ket, and H. Wesseling. 1982. 4-Aminopyridine tablets: a method for the preparation. In-vitro and invivo studies. Pharm. Acta Helv. 57:122-128. 